\title{
Development and Validation of a Liquid Chromatographic Method for the Quantification of Related Compounds in Cyclophosphamide
}

Islam $\mathbf{S}^{*}$, Murugan V, Kumari $\mathbf{P}$ and Shabbhag $\mathbf{N}$

Department of Pharmaceutical Chemistry, College of Pharmaceutical Sciences, Dayananda Sagar University, Bangalore 560078, India

\begin{abstract}
A simple reverse- phase high performance liquid chromatographic method (RP-HPLC) was developed for quantification of the related compounds in Cyclophosphamide. The chromatographic separation was achieved with $\mathrm{C} 18$ column $(250 \times 4.6 \mathrm{~mm}, 5 \mu \mathrm{m}$ particle size) with gradient elution composed of $0.02 \mathrm{M}$ Potassium dihydrogen phosphate $(\mathrm{pH}-7.0)$ as mobile phase-A and $60: 40 \% \mathrm{v} / \mathrm{v}$ Acetonitrile / Water as mobile phase-B at a flow rate of $0.8 \mathrm{~mL} / \mathrm{min}$ and column compartment maintained at $40^{\circ} \mathrm{C}$ for separation. Detection was carried out at $195 \mathrm{~nm}$. The correlation coefficient $(\geq 0.99)$ shows the linearity response against concentration over the range of Limit of Quantification (LOQ). Precision studies showed the Relative Standard Deviation (RSD) values less than $5 \%$ for Cyclophosphamide and its related compounds. The method was substantiated with respect to specificity, precision, linearity, accuracy, limit of quantification, and robustness. The proposed method could be used for routine analysis of Cyclophosphamide formulations.
\end{abstract}

Keywords: Related compounds; Gradient elution; Quantification; Cyclophosphamide

\section{Introduction}

Cyclophosphamide is an anti-cancer agents and chemically known as $\mathrm{N}, \mathrm{N}$-bis(2-chloroethyl)-1,3,2-oxazaphosphinan-2-amine 2-oxide. It is considered as a first line drug for chemotherapy.

Related compounds may arise at any stage of manufacturing or storage condition of drug substances hence these compounds must be detected with accurate analytical method. Accurate analytical method will assess the quality and safety of the drugs.

United States of Pharmacopeia (USP) uses thin layer chromatography (TLC) method for the detection of related compounds. The literature survey reveals that an advance chromatographic technique like Liquid Chromatography-Quadrupole Time of Flight (QTOF) mass spectrometry was used to identify the presence of degradation product in Cyclophosphamide. LC-QTOF is a niche analytical instrument which is unaffordable for many of the quality department. However there is no HPLC technique available for the quantification of related compounds present in Cyclophosphamide. Hence there was a need to develop it which became the purpose of the further study. In this present study, an attempt has been made to develop an accurate, specific and reproducible method for the quantification of related compounds present in Cyclophosphamide [1-3].

HPLC method are capable of reporting precise and accurate results as compared to TLC methods since TLC method are based on visual comparison of spots intensity matching which can be less quantitative in practice.

Hence it was decided to develop a HPLC method to detect the presence of these related compounds in Cyclophosphamide. The chemical nature of the related compounds present in Cyclophosphamide is highly polar in nature. Also these related compounds were lacking the presence of chromophoric group in the molecule. Hence to get a significant amount of peak response from this molecule, PDA detector was used to detect in wide range of wavelength. The wavelength range for the Cyclophosphamide molecule was existing in between $195 \mathrm{~nm}$ to $200 \mathrm{~nm}$. Because of the limited absorption of UV radiation provided by Cyclophosphamide and its related compounds, it was decided to use 195 $\mathrm{nm}$ as suitable wavelength for the quantification. Pulse-amperometric detector (PDA) detector which has the capability to scan a wider range of probable wavelengths instead of a single wavelength is preferred, because the exact lambda max of the analyte maybe unknown initially $[4,5]$.

Due to a high dominance of cancer and its increasing rate each year worldwide, and as cyclophosphamide is the first line drug, it is necessary to develop a simple method which can simultaneously detect and quantify the related compounds present in cyclophosphamide.

\section{Materials and Methods}

\section{Chemicals, reagents and standards}

Cyclophosphamide and its related compounds A, B, C and D were procured from United States of Pharmacopeia (USP) with a potency of $100.0 \%$. HPLC grade of Acetonitrile was supplied by Biosolve. Analytical grade of Potassium dihydrogen phosphate and potassium hydroxide were procured from Merck. Milli-Q water was obtained from Milli-pore system.

\section{Instrumentation}

Liquid chromatography: The analysis was carried out on Waters e2695 High-Performance Liquid Chromatographic system equipped with Atlantis T3 column $(250 \times 4.6 \mathrm{~mm}$ and $5 \mu \mathrm{m}$ particle size $)$ and PDA detector was used for analysis. All the data acquired were processed with Empower 3.0 software (Waters).

*Corresponding author: Sofiqul Islam, Department of Pharmaceutical Chemistry, College of Pharmaceutical Sciences, Dayananda Sagar University, Bangalore 560078, India, Tel: +918050984739; E-mail: Sofiqul7@gmail.com

Received September 10, 2018; Accepted September 22, 2018; Published September 28, 2018

Citation: Islam S, Murugan V, Kumari P, Shabbhag N (2018) Development and Validation of a Liquid Chromatographic Method for the Quantification of Related Compounds in Cyclophosphamide. Pharm Anal Acta 9: 595. doi: 10.4172/21532435.1000595

Copyright: (c) 2018 Islam S, et al. This is an open-access article distributed under the terms of the Creative Commons Attribution License, which permits unrestricted use, distribution, and reproduction in any medium, provided the original author and source are credited. 
Other instruments and equipment: Various analytical columns like Inertsil- $\mathrm{C}_{18}, 250 \times 4.6 \mathrm{~mm} ; 5 \mu \mathrm{m}$ (GL Science) and AtlantisHILIC, $250 \times 4.6 \mathrm{~mm} ; 5 \mu \mathrm{m}$ (Waters) were used during development apart from Atlantis T3 column (Waters). Micropipette (Eppendorff), Analytical weighing balance (Mettler Toledo, Model XP205 and XP26) and $\mathrm{pH}$ Meter (Metrohm, Model 780) were used. The mobile Phase was filtered under the vacuum through $0.22 \mu \mathrm{m}$ membrane filters (Merck, Millipore) [6-8].

\section{Method validation}

Method validation was performed according to the International Conference on Harmonization Guideline (ICH).

Linearity: Linearity was evaluated by determining the response of standard solution of its related compounds at a concentration range of $12.5-150 \mu \mathrm{g} / \mathrm{mL}$. Linearity was performed by injecting LOQ $(12.5 \mu \mathrm{g} /$ $\mathrm{mL}), 25.0 \mu \mathrm{g} / \mathrm{mL}, 50.0 \mu \mathrm{g} / \mathrm{mL}, 75.0 \mu \mathrm{g} / \mathrm{mL}, 100.0 \mu \mathrm{g} / \mathrm{mL}$ and $150.0 \mu \mathrm{g} /$ $\mathrm{mL}$ solutions. Linearity curve was plotted by using the concentration of related compounds at each level versus peak area. Correlation coefficient for Cyclophosphamide and each related compounds was calculated for each calibration curve. ICH recommends that, for the establishment of linearity, a minimum of five concentration levels should be used .Acceptance criteria for correlation coefficient was used as not less than 0.99 [9].

Accuracy: Accuracy of a method is expressed as the closeness of agreement between the value found and the value that is accepted as a reference value.

Accuracy was performed at LOQ level $(12.5 \mu \mathrm{g} / \mathrm{mL}), 50.0 \mu \mathrm{g} / \mathrm{mL}$ and $150.0 \mu \mathrm{g} / \mathrm{mL}$ concentrations of standards. To assess the accuracy, related compounds were spiked with the test solutions at three different concentration level. The Signal-to Noise $(\mathrm{S} / \mathrm{N})$ at different level was quite satisfactory for all the related compounds. The recovery of accuracy results met the acceptance criteria.

Precision: Precision at LOQ level was checked by injecting six injection of $12.5 \mu \mathrm{g} / \mathrm{mL}$. Precision was performed by injecting six injection of $100 \%$ test concentration of standard mixture $(50 \mu \mathrm{g} /$ $\mathrm{mL}$ ). The results for precision along with their acceptance criteria are presented in Table 2.

Quantitation limit (LOQ): LOQ was assessed by injecting test solution concentration level at $12.5 \mu \mathrm{g} / \mathrm{mL}$. Limit of detection (LOD) was assessed from the average signal to noise $(\mathrm{S} / \mathrm{N})$ ratio of the LOQ solution.

The $\mathrm{S} / \mathrm{N}$ ratios for all the peaks at this concentration were above the acceptance criteria which is NLT 10.
Robustness: Robustness was assessed by deliberate variations in method parameters such as flow rate $( \pm 0.2 \mathrm{~mL} / \mathrm{min})$ and column temperature $\left( \pm 2^{\circ} \mathrm{C}\right)$, to measure the capacity of the method to remain unaffected by small variations.

\section{Results and Discussions}

\section{Optimization of the analytical method}

Mobile phase selection: Several mobile phase compositions were tested during the optimization of the method. Finally suitable mobile phase was found for Cyclophosphamide and its related compounds were mobile phase- $\mathrm{A}$ as $0.02 \mathrm{M}$ potassium dihydrogen phosphate buffer with $\mathrm{pH}$ adjusted to 7.0 and mobile phase- $\mathrm{B}$ as Acetonitrile: Water in the proportions of $60: 40 \% \mathrm{v} / \mathrm{v}$. This combination of mobile phase provided well resolved peak which significantly improve the peak shape of the related compounds. The mobile phase was filtered and degassed.

Analytical column selection: These related compounds and Cyclophosphamide were injected and run through different columns. Atlantis T3 column was is designed for separation of polar compound, hence it was found as suitable column for the separation and elution of this related compounds.

Column temperature: The column temperature was chosen as $40^{\circ} \mathrm{C}$ for separation of these related compounds.

Flow rate and injection volume: The flow rate of the mobile phase was varied from $0.5 \mathrm{~mL} / \mathrm{min}$ to $0.8 \mathrm{~mL} / \mathrm{min}$ to get the good optimal resolution between the obtained peaks. Injection volume was set as 50 $\mu \mathrm{L}$.

Gradient program selection: Along with the flow rate, the gradient program was also modified. Initially at 30 minutes the proportion of Mobile Phase-A: Mobile Phase-B was $75: 25 \% \mathrm{v} / \mathrm{v}$ and in the final, the composition was changed to $55: 45 \% \mathrm{v} / \mathrm{v}$ from 30 to 50 minutes to decrease the polarity, so that the components are retained in the column for a longer time.

Attempts to detect related compound-C: Among the four related compounds, related compound-C did not get detected. The absence of strong UV chromophore in this related compound makes conventional UV detector not sensitive enough to detect the low level of related compounds. Thus, an attempt was made to derivatise related compound-C with derivatising reagents to check if it gets detected. Two derivatizing agents like fluorescamine and fluoro-2,4-dinitro benzene were made to react with related compound-C and was injected into the column. But, from the chromatograms it was concluded that related compound-C did not react with any of the derivatising agents. Thus it

\begin{tabular}{|c|c|c|c|c|c|}
\hline \multirow[b]{2}{*}{ Parameters } & \multirow[b]{2}{*}{ Acceptance criteria } & \multicolumn{4}{|c|}{ Results } \\
\hline & & Related Compound A & Related Compound B & Related Compound D & Cyclophosphamide \\
\hline \multirow{3}{*}{ System Suitability } & $\begin{array}{l}\text { Theoretical plates should be NLT } \\
2000\end{array}$ & 14567 & 7255 & 7373 & 23542 \\
\hline & $\begin{array}{l}\text { The tailing factor should be NMT } \\
2.0\end{array}$ & 1.3 & 1.4 & 1.7 & 1.2 \\
\hline & $\begin{array}{l}\text { Mean } \pm \text { RSD of six replicate } \\
\text { injection of peak area should be } \\
\text { NMT } 5.0 \%\end{array}$ & 0.4 & 0.4 & 0.7 & 0.9 \\
\hline Specificity & $\begin{array}{l}\text { No peak interference should be } \\
\text { observed at the retention times of } \\
\text { cyclophosphamide and its related } \\
\text { compounds from blank }\end{array}$ & \multicolumn{4}{|c|}{$\begin{array}{l}\text { No peak interference was observed at the retention times of cyclophosphamide and its listed impurities by } \\
\text { the injected blank, mobile phase injection. }\end{array}$} \\
\hline \multicolumn{6}{|c|}{ Where NMT: Not more than, NLT: Not less than, RSD: Relative Standard deviation. } \\
\hline
\end{tabular}


was confirmed that related compound $\mathrm{C}$ will not be detected any of this method. Another separate method need to be develop to quantify the related compound C [10].

Sample preparation: Standard solution was prepared at concentration of $50 \mu \mathrm{g} / \mathrm{mL}$ and sample was prepared at concentration of $5 \mathrm{mg} / \mathrm{mL}$. Linearity solution was prepared at various concentration level by a single preparation of LOQ $(12.5 \mu \mathrm{g} / \mathrm{mL}), 25.0 \mu \mathrm{g} / \mathrm{mL}, 50.0 \mu \mathrm{g} /$ $\mathrm{mL}, 75.0 \mu \mathrm{g} / \mathrm{mL}, 100.0 \mu \mathrm{g} / \mathrm{mL}$ and $150.0 \mu \mathrm{g} / \mathrm{mL}$ solutions. Milli Q water was used as a diluent to prepare the solutions.

\section{Validation of HPLC method}

The present study was designed to develop a validated, simple and reliable HPLC method for the quantification of the related compounds.

System suitability: System suitability parameters were calculated as per the USP guidelines to verify the chromatographic system was adequate for analysis. System suitability solution was prepared using the standard mixture solution of Cyclophosphamide and its related compounds at a concentration of $50 \mu \mathrm{g} / \mathrm{mL}$ as per the method and injected six times into the HPLC system. The System suitability parameters were evaluated. Results are presented in Table 1, indicating the good performance of the system (Figure 1).

Specificity: To confirm the specificity of the related compounds were spike to test solution and injected into the HPLC system and compare the chromatogram with the blank. And results founds that no interference peaks were found in blank (Milli-Q water) and mobile phase interfering with retention time (Rt) of analyte, hence this method is specific to its intended use. Chromatogram for Specificity experiment was shown in Figure 2.
Precision Linearity and accuracy: Precision of the method was evaluated by injecting six injection of spike solution of related compounds with the test solution. The \%RSD of the related compounds were calculated and tabulated in Table 2 . Linearity was performed by covering the QL level to $150 \%$ by using the concentration of sample $(5 \mathrm{mg} / \mathrm{mL})$.The peak area of each individual compounds were plotted against the corresponding concentrations. A study of accuracy was conducted by spiking the related compounds to the sample at different concentration level. The \% recoveries were calculated and tabulated in Table 3.

Limit of detection and quantification limit (LOQ): Determined limit of detection and quantification limit based on the $\mathrm{S} / \mathrm{N}$ method. The $\mathrm{S} / \mathrm{N}$ ratio was derived about 3.0 for limit of detection and 10.0 for the limit of quantification. $\mathrm{S} / \mathrm{N}$ ratio of each related compounds were presented in Table 2.

Robustness of the method: Robustness of the method is evaluated through minor but deliberate changes in method and measured the ability of the method remained unaffected from these changes. These deliberate changes were in flow rate and temperature variation. Flow rate was varied from $0.6 \mathrm{~mL} / \mathrm{min}$ to $1.0 \mathrm{~mL} / \mathrm{min}$ and temperature was varied from $38^{\circ} \mathrm{C}$ to $42^{\circ} \mathrm{C}$. System suitability solution was injected to each varied condition. The results obtained from the system suitability injection were quite satisfactory. Hence it can be confirmed that method is robust $[11,12]$.

\section{Conclusion}

This HPLC method was quite convenient method for the quantification of related compounds in Cyclophosphamide. The developed method was validated according to ICH guidelines. The

\begin{tabular}{|c|c|c|c|c|c|}
\hline \multirow{2}{*}{ Parameters } & \multirow{2}{*}{ Acceptance criteria } & \multicolumn{4}{|c|}{ Results } \\
\hline & & Related Compound A & Related Compound B & Related Compound D & Cyclophosphamide \\
\hline Precision & \multirow{2}{*}{$\begin{array}{l}\text { Mean } \pm \text { RSD calculated } \\
\text { on six determinations for } \\
\text { spiked sample should be } \\
\text { within } 10.0 \%\end{array}$} & 2.4 & 1.6 & 4.6 & 0.4 \\
\hline Intermediate Precision & & 0.3 & 1.2 & 0.6 & 0.9 \\
\hline Linearity & $\begin{array}{l}\text { The correlation coefficient } \\
\text { should be NLT } 0.99\end{array}$ & 0.9996 & 0.9999 & 0.9975 & 0.9979 \\
\hline Quantitation limit (QL) & $\begin{array}{l}\mathrm{S} / \mathrm{N} \text { ratio of each related } \\
\text { compound in } \mathrm{QL} \text { solution. }\end{array}$ & 85 & 17 & 43 & 87 \\
\hline \multicolumn{6}{|c|}{ Where NLT: Not less than } \\
\hline
\end{tabular}

Table 2: Validation results Summary.

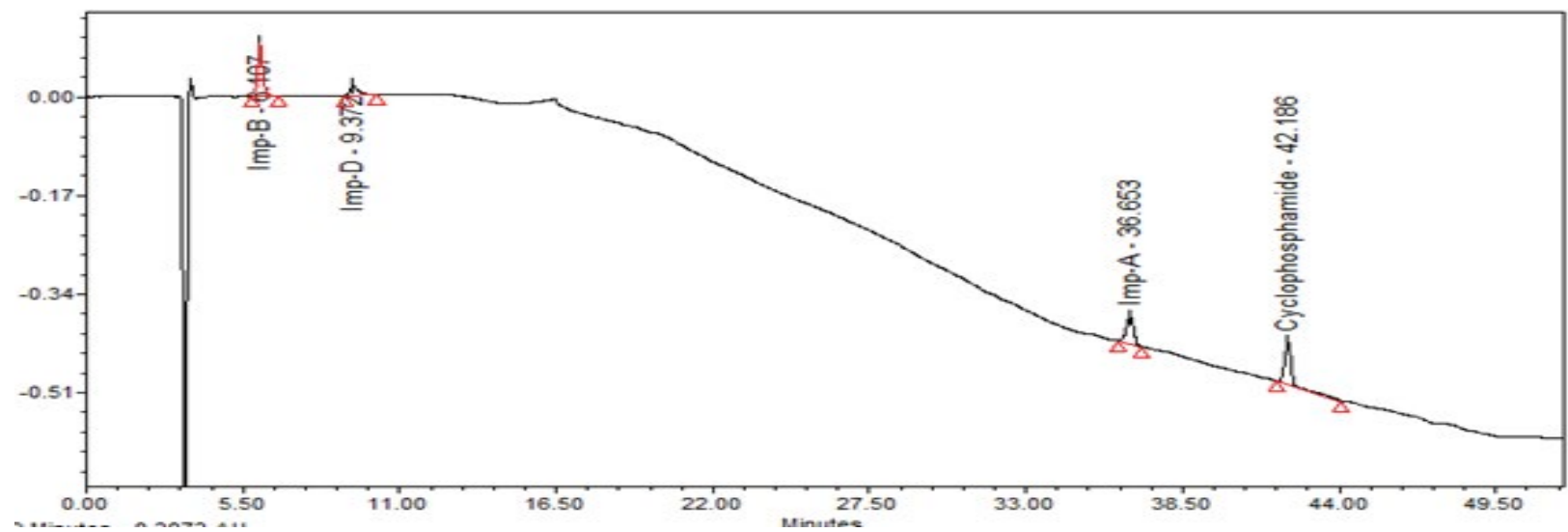

Figure 1: Chromatogram of system suitability injection. 
Citation: Islam S, Murugan V, Kumari P, Shabbhag N (2018) Development and Validation of a Liquid Chromatographic Method for the Quantification of Related Compounds in Cyclophosphamide. Pharm Anal Acta 9: 595. doi: 10.4172/2153-2435.1000595

Page 4 of 4

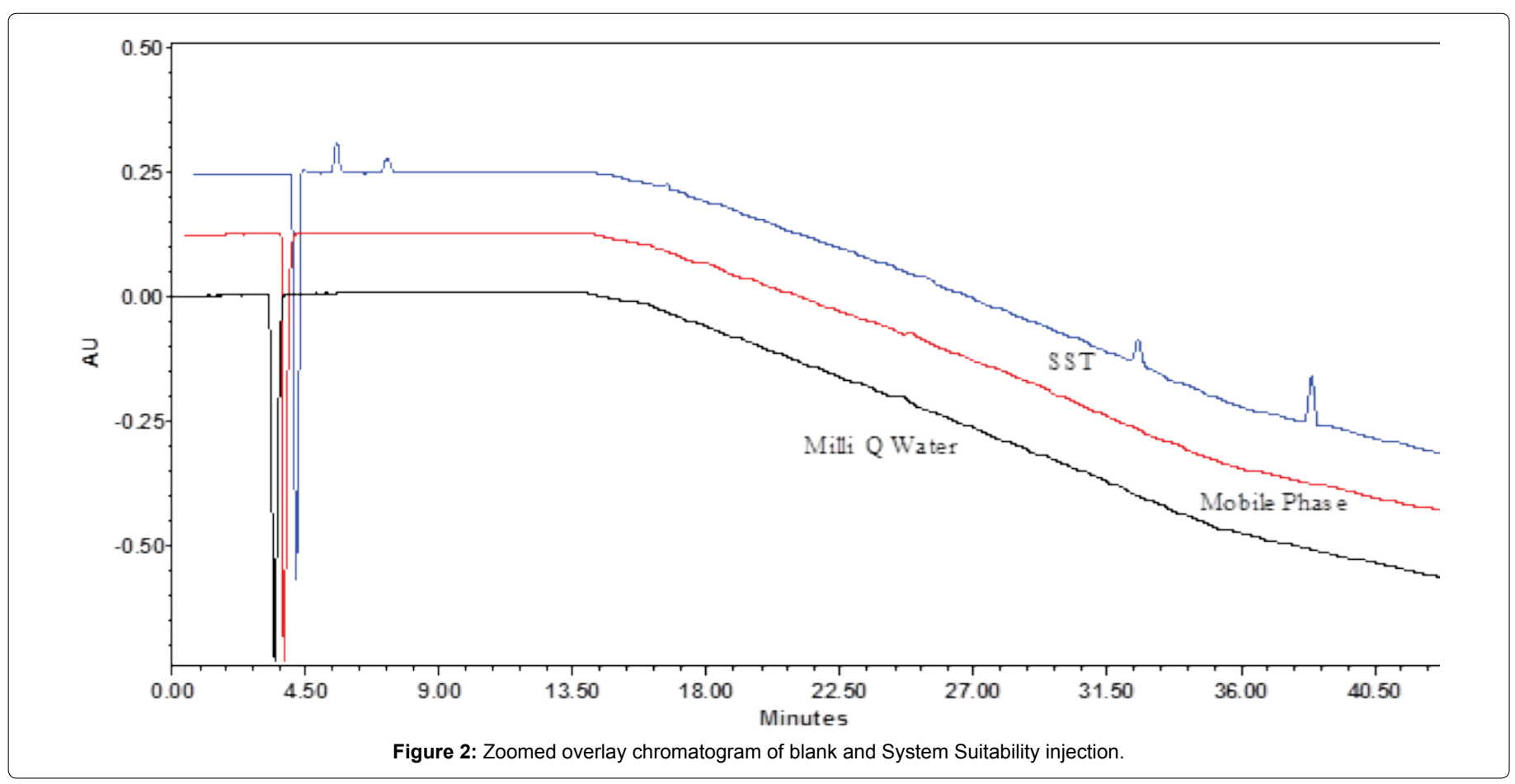

\begin{tabular}{|c|c|c|c|c|c|c|}
\hline \multirow[b]{2}{*}{ Parameters } & \multirow[b]{2}{*}{ Acceptance criteria } & \multirow[b]{2}{*}{ ID } & \multicolumn{4}{|c|}{ Results } \\
\hline & & & $\begin{array}{c}\text { Related Compound } \\
\text { A }\end{array}$ & $\begin{array}{c}\text { Related Compound } \\
\text { B }\end{array}$ & $\begin{array}{l}\text { Related Compound } \\
\text { D }\end{array}$ & Cyclophosphamide \\
\hline \multirow{3}{*}{ Accuracy } & \multirow{3}{*}{$\begin{array}{l}\text { Recoveries of each } \\
\text { related compound must } \\
\text { be within } 80-120 \%\end{array}$} & Level 1 & 105 & 99 & 90 & 91 \\
\hline & & Level 2 & 111 & 96 & 92 & 92 \\
\hline & & Level 3 & 105 & 90 & 102 & 91 \\
\hline Robustness & $\begin{array}{l}\text { System suitability } \\
\text { criteria should } \\
\text { be met at each } \\
\text { condition change. }\end{array}$ & & System suitabi & ity criteria met the acc & otance criteria at each & ondition. \\
\hline
\end{tabular}

Table 3: Validation results Summary.

proposed method is quite simple. Results obtained from the validation study of the method were quite satisfactory. HPLC method will determine the presence of accurate amount of related compounds in drug substances Hence this method can be easily applied for the quality control of Cyclophosphamide and its related compounds in order to minimize the cost and time of analysis.

\section{References}

1. USP Monographs: Cyclophosphamide. Pharmacopeia.cn

2. Vitthal D, Dhakane, Ubale MB (2016) Development and validation of a reverse phase high performance liquid chromatographic method for the estimation of cyclophosphamide in bulk drug. Int J Pharm Pharm Sci 5: 185-189.

3. Shivakumar G, Dwivedi J (2016) Identification of degradation products in cyclophosphamide API by LC-QTOF mass spectrometry. J Liq Chromatogr Relat Technol 38: 190-195.

4. Ahmed M, Usman M, Madni A, Zubai M (2011) A fast and simple HPLC-UV method for simultaneous determination of three anti-cancer agents in plasma of breast cancer patients and its application to clinical pharmacokinetics. J Pharm Pharmacol 5: 915-922.

5. Bai F, Fraga CH, Tagen M (2009) Simultaneous determination of cyclophosphamide and carboxyethylphosphoramide mustard in human plasma using online extraction and electrospray tandem mass spectrometry (HTLCESI-MS/MS). J Chromatogr 877: 1709-1715.

6. Castro FAD, Scatena GDS, Cass QB, Simões BP, Lanchote VL (2014) Analysis of cyclophosphamide and carboxyethylphosphoramide mustard enantiomers in human plasma and application to clinical pharmacokinetics. J Chromatogr 971: 971-975.
7. Larson RR, Khazaeli MB, Dillon HK (2003) Development of an HPLC Method for simultaneous analysis of five antineoplastic agents. Appl Occup Environ Hyg 18: 109-119.

8. Rastkari N, Ahmadkhaniha R, Alehashem M (2016) Rapid method for the determination of cyclophosphamide and ifosphamide in urine trace levels by gas chromatography-mass spectrometry. Int J Pharm Clin Res 8: 289-292.

9. Sanson AL, Silva SCR, Martins MCG, Giusti-Paiva A, Maia P P, et al. (2011) Liquid-liquid extraction combined with high performance liquid chromatrographydiode array-ultra -violet for simultaneous determination of antineoplastic drugs in plasma. Braz J Pharm Sci 47: 363-371.

10. Goyal PK, Belwal C, Parmar SA, Vardhan A (2013) Validated RP HPLC method for the related substances in Imatinib Mesylate. Indo Am J Pharm Sci 3: 2582 2591.

11. Prasad V, Pranothi M, Diwan VP, Kishore C (2013) Development of HPLC method for the identification related substances and assay of zoledronic acid in a tablet dosage form. Br Biomed Bull 1: 044-055.

12. Somasekhar V (2014) Optimization and validation of an RP HPLC method for estimation of 6-mercaptopurine in bulk and pharmaceutical formulations. Braz J Pharm Sci 50:793-797. 